\title{
Mineiros em movimento: flutuação dos significados das práticas alimentares e agrícolas a partir do fluxo rural-urbano
}

\author{
RODICA WEITZMAN \\ Doutoranda em Antropologia Social (Museu Nacional-UFRJ) \\ Rio de Janeiro, Brasil \\ rodicablues@yahoo.com.br
}

\begin{abstract}
Resumo O objetivo deste trabalho é analisar a evolução das representações em torno de alimentos e comidas por parte de pessoas que vieram da área rural em Minas Gerais e se deslocaram para as comunidades Morro dos Prazeres e Escondidinho, localizadas na cidade do Rio de Janeiro. Os esquemas valorativos que determinam as escolhas alimentares no contexto urbano - que passam por rupturas, transformações e ressignificações - são bastante elucidativos da mobilidade que caracteriza este processo de idas e voltas no espaço e no tempo. A ligação entre o passado e o presente, entre a roça e a cidade se renova e se reatualiza no cerne das práticas alimentares e agrícolas exercidas pelos mineiros, na produção daquilo que remete ao passado, mas ao mesmo tempo, gera novos significados a partir do momento presente.
\end{abstract}

palavras-chave: mobilidade; lembranças; hábitos alimentares; Minas Gerais; roça

\section{Contextualização do trabalho etnográfico'}

A ESPINHA DORSAL DESTE ESTUDO etnográfico é justamente as histórias contadas pelas pessoas que vieram de diversas regiões do estado de Minas Gerais e atualmente residem em Morro dos Prazeres e Escondidinho, duas comunidades próximas que são localizadas na região central da cidade de Rio de Janeiro. ${ }^{2}$ Estas comunidades estão localizadas na interseção entre a Zona Sul e a Zona Norte, no bairro de Santa Teresa. Hoje, têm uma população de 3.528 pessoas e abrigam 928 domicílios. Em 1960, foi registrado que a maior parte dos moradores veio do estado ou do município do Rio de Janeiro, mas cumpre salientar que os moradores originários de outros estados, vinham em maior número de Minas Gerais e, em segundo, da Paraíba (IBGE, 2000).

1 Acho pertinente fazer algumas ressalvas ao respeito das convenções empregadas neste texto. Neste sentido, vale salientar os seguintes pontos: a) Utilizo itálico para problematizar termos e expressões, (alguns dos quais têm sido empregados por meus interlocutores), e para incitar um exercício de reflexão sobre a situação retratada; b) Aspas duplas ("xx") serão empregadas para denotar as falas dos informantes ou para citações bibliográficas 2 Este trabalho etnográfico se refere à pesquisa realizada para elaboração da dissertação de mestrado da autora: Entre a roça e a cidade: Um processo de invenção de práticas alimentares e agrícolas (PPGAS/MN, 2011). 
Para contextualizar melhor a localidade onde realizei a pesquisa etnográfica, vale ressaltar as subdivisões geográficas, onde concentram determinadas populações de acordo com seu lugar de origem, e o que aponta para a força das identidades regionais na composição interna destas comunidades. $\mathrm{Na}$ Colina, que se refere à área no alto do Morro dos Prazeres, há uma parte denominada Morro dos Paraíba e na comunidade chamada de Escondidinho, tem uma rua com nome de Rua dos Mineiros. No periodo de 1960 a 1975, a Rua dos Mineiros se constituiu enquanto um foco central da população mineira porque foi onde a maior parte dos mineiros que vieram se agregaram, na auge do fluxo migratório.

Vários residentes na Rua dos Mineiros contam que apesar de ainda residirem "alguns mineiros", a rua foi perdendo esta característica tão marcante e foi se diluindo de tal forma que, para alguns, o nome da rua perdeu seu significado original. Eliza Rosa Brandão da Silva, Presidente da Associação da Sociedade de Amigos de Morro dos Prazeres, alega que as distinções regionais diminú́ram com o tempo por causa do processo de adensamento populacional. Como ela mesma afirma: "Hoje tem mais mistura entre as pessoas porque há menos espaço".

\section{Introdução}

Uma chave de leitura neste empreendimento intelectual é que o campo e a cidade deveriam ser apreendidos numa visão dialética, tendo como foco de análise os modos de vida e valores que cada um destes âmbitos exprime. Portanto, a intenção deste trabalho é compreender de que forma este vínculo entre o passado e o presente, entre a roça e a cidade se renova e se reatualiza no cerne das práticas alimentares e agrícolas.

A decisão de focalizar as transformações nas práticas alimentares e agrícolas como fio condutor do exercício etnográfico foi tomada a partir dos subsídios que surgiram ao longo do trabalho de campo. Isto é, nas histórias contadas, houve menção de alimentos e comidas com bastante ênfase, de forma espontânea. Assim, o que ficou perceptível é a centralidade destes elementos, ao evocarem o processo de deslocamento e a inserção de pessoas oriundas da área rural no meio urbano.

Como destaca Mintz (2001), as condutas e práticas em relação à comida e à alimentação estão vinculadas ao "sentido de nós mesmos e à nossa identidade social". Dentre um estudo realizado sobre os hábitos alimentares em camadas de baixa renda em várias regiões do Brasil,Velho (1977) discorre sobre a importância da alimentação na consolidação da identidade social, a partir de um esquema referencial ancorado no tempo e no espaço, o que constitui um dos traços de minha abordagem epistemológica e metodológica. Segundo o autor:

$\mathrm{Na}$ verdade, a própria trajetória dos grupos e indivíduos no espaço (sobretudo nos casos de migração) e no tempo (visão de passado e do presente) é marcada pela alimentação e suas modificações, o que acaba por ser também incorporado à identidade social (Velho, 1977, p. 45).

Contudo, cabe destacar que pessoas que vivenciam os fluxos migratórios são importantes agentes de mudança no que tange aos hábitos alimentares, por experimentarem intensamente os cruzamentos e as diferenciações entre a "comida daqui" - referente ao lugar onde se residem na atualidade - e a "comida de lá" - referente ao seu lugar de origem. Assim, via de regra, a relação que se constrói com o universo da comida e da alimentação é mutável; tende a ser moldada pelo fluxo de emoções que são suscitadas a partir das lembranças de um passado que foi vivido em um outro espaço geográfico.

Frequentemente, os mineiros entrevistados durante o período de pesquisa etnográfica falavam de sua saudade das comidas mineiras de sua terra natal e de sua estranheza com o que constitui a comida carioca. O tempo de cozimento, a forma de preparo e o sabor da comida são fatores considerados nesta avaliação. Há frases que fazem referência às lacunas na comida "carioca", como "a comida aqui não sustenta", "botam no gás e queimam a comida", "aqui todo é congelado".

Os mineiros falavam ainda do processo de trânsito alimentar: do seu esforço para trazer alimentos, plantas e mudas da roça para cidade, de sua paixão pela plantação, dos seus vários experimentos agrícolas e de sua busca incessante por plantas, alimentos e mudas nos quintais dos vizinhos e nas áreas verdes que rodeiam as comunidades urbanas.

Em suma, neste trabalho, abordo de modo mais frontal o lugar do alimento enquanto componente de um modelo referencial que se constrói a partir dos contrastes e paralelos entre dois espaços geográficos - a roça e a cidade e, dois tempos - o passado e o presente. Focalizo os esquemas valorativos e componentes ideológicos que determinam as escolhas alimentares destes mineiros que estão imersos neste fluxo rural-urbano.

O trânsito rural-urbano se faz presente na flutuação dos significados atribuídos às categorias alimentares no contexto observado. Diversas facetas das tradições alimentares e agrícolas que foram legados de um passado servem como os principais vetores do movimento inventivo, na produção daquilo que remete ao passado, mas ao mesmo tempo, gera novos significados.

\section{Jogos de memória, gramáticas emocionais e práticas alimentares e agrícolas}

As duas demarcações territoriais nas comunidades pesquisadas que representam agrupamentos por afiliação ao mesmo lugar de origem -Rua dos Mineiros e Morro dos Paraíba respectivamente- são reflexos de 
como os fluxos se organizam. Este processo de consolidação de identidades regionais se concretiza espacialmente, pelas demarcações feitas, mas começa anteriormente à vinda. Isto é, há uma articulação prévia à vinda para cidade e o movimento de vir para cidade exerce um efeito cascata.

A maior parte dos mineiros veio porque um parente, amigo(a) ou conhecido(a) já tinha vindo para Morro dos Prazeres ou Escondidinho e muitos chegaram em busca de determinadas referências - os primeiros que vieram- um núcleo de mineiros, todos oriundos de Ubaporanga $^{3}$, que foram os primeiros a chegar e acolhiam os recém-chegados. Além de ajudar na procura de moradia, eles também colaboravam com os recém-chegados em busca de emprego. Portanto, nota-se que, desde o início, o processo de ocupação dos territórios foi se configurando a partir de afinidades - em termos identitários - e as demarcações passaram a representar códigos de identificação ao navegar por este tecido imbricado de relações.

Para meus interlocutores, a categoria operante é ser mineiro - um traço constituinte da identidade e um elemento-chave no seu processo de auto-identificação, que não diminui em intensidade com o passar dos anos, mesmo depois de se deslocar para outro estado. Como afirma um informante, oriundo de Caratinga: "Nunca esqueço que sou mineiro. Se alguém perguntar de onde sou, sempre respondo que sou de Minas Gerais. Não importa que estou no Rio há 42 anos - nunca vou deixar de ser mineiro".

Ser de um determinado lugar se torna bastante significativo no mapeamento das relações. Vale salientar que o exercício de questionar os pertencimentos familiares e locais não apenas era uma iniciativa empreendida por mim, na função de pesquisadora, que considerava tal informação pertinente para o esboço de minha investigação etnográfica. Também era importante para os próprios mineiros, que estreitam laços a partir da verificação de confluências de origem. Como afirma Comerford (2006, p. 4): "Incluir cada indivíduo em alguma família e buscar sua origem em algum lugar evidencia o quanto isso é crucial no quadro de referências de navegação social desse universo".

Neste contexto, ser mineiro remete ao seu lugar de origem - a roça. A frase de Dona Rosa, moradora de Morro dos Prazeres e oriunda de Ubaporanga, exprime esta relação intricada com a roça: "A gente nunca esquece da roça. Parece que está dentro da gente". Para estes mineiros que nunca esquecem que são mineiros, e que nunca esquecem do seu lugar de origem, a roça, o trânsito não se refere apenas a um deslocamento entre dois pontos - campo e cidade - mas envolve também o movimento incessante de ir e vir na reconstrução das memórias que transgridam as bases desta suposta polaridade e proporcionem a criação de novos registros.

Tomo como referencial a visão sobre memória apresentada por Lambek (1996), como um processo intersubjetivo e dialógico, envolvendo um processo de engajamento contínuo com o ato de lembrar. Também, aproveito das contribuições de Barth (2000), ao enfatizar a importância de levar em consideração o fato de que o significado de determinadas situações ou objetos é construído em relação, no próprio ato da interação. Para o autor, a relação com memória não é estática e as pessoas lembram e relembram o que foi vivido a partir do lugar que estejam ocupando em um determinado momento. A decorrência lógica desta posição é que "os atos permanecem sempre contestáveis e seu significado pode ser reescrito" (Barth, 2000, p. 176). Da mesma forma, pode-se deduzir que as expressões emocionais também são bastante variáveis e flutuantes; o que é vivido no plano afetivo é condicionado pelos jogos de memória e é marcado pela temporalidade.

Assim, nas trajetórias dos mineiros, a memória engendra as relações costuradas com as pessoas, objetos e coisas que se agregam num universo de aqui e agora - no contexto da cidade- mas que, ao mesmo tempo, se remetem ao que foi vivido - na roça. Isto posto, para compreender os hábitos alimentares destes mineiros que se deslocam para o espaço urbano carioca, será indispensável manter, como pano de fundo, o quadro referencial entre o passado e o presente, a roça e a cidade, que é subjacente a este sistema de significados (Mintz, 1990).

\subsection{A lembrança saudosa da roça e das comidas "de lá"}

Há tentativas para manter contato com o lugar de origem através de viagens periódicas para comemorações com familiares e participações em festas, como a Festa dos Ausentes ${ }^{4}$. Viagens coletivas também são organizadas e realizadas para viabilizar a participação dos mineiros no processo eleitoral, de forma que a conexão com as dinâmicas políticas locais se mantenha, apesar da distância fisica.

3 Ubaporanga é um município da região leste de Minas Gerais, próximo a Caratinga. No trabalho de campo, foi possível constatar que a maior parte dos mineiros que moram no Morro dos Prazeres e Escondidinho veio deste município.

4 A Festa dos Ausentes é um evento que acontece anualmente em Ubaporanga, MG- onde realizei uma parte do meu trabalho de campo desde 1981. Busca a junção entre os ausentes (quem se deslocou para fora da comunidade local) e os presentes (moradores do município), com o intuito de estreitar os laços intra e interfamiliares e reforçar os vínculos com o lugar de origem. A ausência de um segmento da população do seu lugar de origem por causa de sua ida para a área urbana torna-se um marco constitutivo de sua identidade e um motivo de celebração em determinada época do ano. 
As constantes idas e voltas entre a roça e a cidade ilustram a potência do sentimento de saudade ${ }^{5}$, que também se traduz no anseio de trazer alguns fragmentos do universo da roça para o ambiente da cidade. $\mathrm{O}$ alimento serve como um canal de intermediação entre os dois universos, uma forma de recuperar parte do que representa o lugar de origem. Assim, quando os que se deslocaram para Morro dos Prazeres e Escondidinho visitam seus lugares de origem, priorizam alguns alimentos específicos para trazer como se fossem emblemáticos das trajetórias traçadas e histórias vividas.

Dona Francisca, moradora de Morro dos Prazeres, explica este processo de trânsito alimentar:

Eu gosto de trazer para cá aquelas coisas que me lembram daquele tempo na roça - sabe? Às vezes, me dá uma saudade de comer aquele feijão, colhido no pé... é outro sabor. E as laranjas do quintal - tem um saber tão diferente daquelas que se compra no sacolão - De vez em quando, me dá aquela vontade de chupar laranja no pé, como fazia quando era criança. E o café - é o que mais me dá saudade. Não consigo acostumar com aquele café comprado aqui na cidade... já perdeu o gosto. Não é a mesma coisa.

Os alimentos que Dona Francisca traz são os alimentos que preservam sabores e gostos que se remetem a um tempo vivido. Também, refletem vivências marcadas pela afetividade, como "chupar laranja no pé", nos tempos de ser criança.

Há parentes que repetidamente mandam alimentos e comidas via transporte público e há encomendas feitas para quem vai e volta com frequência. Seu Sebastião, dono de uma farmácia em Ubaporanga, MG, e grande conhecedor da história local e regional, discorre sobre esta movimentação em torno das "comidas daqui":

Já observei há muito tempo que quem saiu de Ubaporanga não consegue esquecer estas comidas daqui. Mães mandam taioba, couve, queijo, linguiça e galinha caipira para seus filhos no Rio de Janeiro. Eles gostam de galinha caipira para fazer sopa - para fazer frango com macarrão grosso - fica amarelinho pela gordura do galo. Quando alguém vem aqui, pede um montão de coisas - pede goiabada cascão da casa de fulano, pede para arranjar um tipo de quiabo grosso que só tem aqui. Pede fubá da roça - que é bem mais grosso. Falam assim - traz aquela farinha torrada da avó. Sabem que é somente aquela que serve. [Sebastião]

No seu estudo sobre a comida e a memória social no contexto de uma família judia sefardi radicada no Brasil, Amon \& Menasche (2008) fazem referência ao conceito da "voz da comida", trazida pela autora Hauck-Lawson $(1992,1998)$ como uma forma de testemunhar o papel dinâmico que a comida desempenha no processo de comunicação e interação social. Segundo as autoras: "Se a comida é uma voz que expressa significados, como a fala, ela pode contar histórias". (Amon; Menasche 2008)

Dessarte, no contexto desta pesquisa, o depoimento acima, quando faz referência à aquela "farinha torrada da avó", demonstra de que forma a comida, que se remete aos tempos vividos na roça, tem sua própria voz - uma voz ancorada nas "histórias que os alimentos contam" (Mintz, 1996) dentro das trajetórias individuais e coletivas. Sendo assim, as qualidades das comidas "de lá" que são ressaltadas em alguns fragmentos das histórias contadas põem em descoberto uma complexa gramática de emoções que são suscitadas ao lembrar de um tempo vivido.

Nos relatos dos mineiros sobre as comidas e alimentos oriundos da roça, várias qualidades são mencionadas, entre elas, seu frescor, por serem colhidos na hora, e sua pureza, por serem plantados "sem química". Parece haver um viés romântico e sentimentalista em relação às vantagens da comida da roça, explicada em parte por uma cadeia de relações imbricadas entre o processo de plantação - que envolve uma série de procedimentos técnicos - e a colheita e consumo dos alimentos. Os seguintes depoimentos explicitam os enquadramentos do alimento - emblemático da roça - nas representações dos mineiros:

Tinha que comprar tudo aqui. Lá apanhava na hora. Naquela época, não tinha nem geladeira. Matava porco. Não tinha congelado. Aqui, até o frango tem um gosto diferente. [Josefina]

$\mathrm{Na}$ roça, era mais carne de porco. Matava, fazia gordura. Aqui chega tudo cozido, porque bota no gelo. O gelo cozinha qualquer coisa. Tira o gosto da comida. [Francisca]

E angu feito de milho novo? Chega a dar uma liga. O gosto é tão diferente. [Maria]

Custou acostumar com a fruta aqui. Lá, pegava no pé. Tudo que você pega tem vitamina. Aqui, compra e logo depois fica amassada. Quando compro uma couve, logo depois que chego em casa, já está murcha. [Helena]

Merece destaque esta última citação, que traz a lembrança das frutas que eram consumidas "lá", associadas com a vivência de "pegar no pé". Isso revela que alguns alimentos carregam inscrições de um tempo vivido e estas marcas são constituintes da "VOZ da 
comida" (Hauck-Lawson, 1992, 1998), de modo que interferem nas relações forjadas com o ato de comer.

Cito a seguir as significações conferidas ao café, a partir de um referencial contrastivo que ressalta as qualidades inerentes ao café colhido no contexto da roça em comparação com o café consumido na cidade. Segundo os mineiros, o café era mais grosso, mais pesado no contexto da roça e, geralmente, se tomava o café com "garapa" ou "se moía a cana e colocava no café". Hoje, na cidade, os entrevistados descrevem o café consumido como um "café que tem mistura" e "fica armazenado por muito tempo". Dizem que "não se sabe de onde vem", o que denota a falta de controle sobre o processo produtivo que gera o produto, condições que não existiam no contexto da roça.

Os depoimentos citados acima explicitam um jogo de oposições entre "lá" e "aqui" - subjacente ao esquema referencial contrastivo que orienta os enquadramentos dos alimentos e comidas. Ao discorrerem sobre as mudanças ocorridas nos alimentos a partir de sua vinda para cidade, três dos mineiros entrevistados fazem referência às alterações no gosto. As alterações no gosto são relacionadas com as estratégias de preparo. $\mathrm{O}$ "angu feito de milho novo", que "chega a dar liga" no processo de preparação, tem um "gosto diferente" que o angu comprado na cidade. No caso das carnes congeladas, o efeito do gelo que "cozinha qualquer coisa" e tira esse gosto especial que se preservava na roça, quando se matava o porco e consumia a carne na hora.

Parece haver uma ligação entre o frescor e a pureza dos alimentos e a preservação do seu sabor diferenciado. Entretanto, uma observação importante é que não necessariamente possuir estas qualidades - frescor e pureza - implica serem alimentos mais saudáveis. Dentre os mineiros enraizados em Morro dos Prazeres, há alguns que enfatizam a importância de usar gordura do porco, que dá um "gosto especial" para a comida, mesmo reconhecendo que talvez não seja tão recomendável do ponto de vista de sua salubridade.

Como afirma Dona Sebastiana, tia do Seu Natalino e oriunda de Ubaporanga "a comida tem que ser feita com gordura do porco. Se for feita com óleo, não fica boa". Dona Eli, oriunda de Caratinga conta sobre como preparava gordura de porco na roça e expressa a importância do seu uso na comida:

Gordura do porco - pode ser um pouquinho de nada, mas dá um sabor. Lá, matava um porco, separava a carne, o torresmo. Aquela carne ficava curtindo... ficava fresca.
Fritava muito bem... ficava na gordura. Ficava um mês. Fomos criados com a gordura de porco. Quando refogava com couve - que delícia que era. [Eli]

Aparecida, oriunda de Ubaporanga, expressa a dificuldade de obedecer à regra imposta pelos médicos, em relação à exigência de substituir gordura de porco por óleo:

Se pudesse colocar gordura de porco na comida, seria muito melhor. Perde aquele gosto da comida com óleo. Mas, não posso mais. Tenho pressão alta. Antes a gente não sentia nada. Agora, veio pressão alta, estas coisas. $\mathrm{O}$ médico já me falou para não comer mais gordura de porco, mas não consigo acostumar com óleo. [Aparecida]

Estas distinções entre alimento saudável e não saudável começaram a operar a partir da vinda para cidade, principalmente com a imposição de prescrições nutricionais, advindas dos médicos e nutricionistas, além da prática de assistir programas na televisão que divulgam informações sobre alimentação saudável. O que é interessante observar aqui é de que modo aquilo que "dá um gosto especial" para a comida, representando uma tradição que foi apreendida no contexto da roça, passa por um processo de ressignificação no contexto da cidade e se torna uma pratica não saudável, que portanto, precisaria ser suprimida.

Nota-se aqui a resistência, por parte de vários mineiros, de abrir mão de um hábito alimentar que foi herdado durante os tempos vividos na roça e está ligado com uma série de lembranças saudosas, para adotar novas práticas que supostamente seriam menos maléficas, de acordo com o conhecimento técnico da classe médica. Desta maneira, dois tipos de saber se confrontam: por um lado, há aquele saber que se constrói a partir da vinculação entre o processo produtivo e as qualidades inerentes ao alimento preparado (frescor e pureza), tendo como base as experiências vividas no contexto da roça, e por outro lado, há aquele saber que se constrói a partir de estudos técnicos sobre os valores nutricionais dos alimentos, realizados pelos nutricionistas e médicos. Mesmo sabendo que um alimento pode exercer efeitos nocivos sobre a saúde, ${ }^{6}$ muitos mineiros, como Aparecida, prescindem das prescrições nutricionais e se apegam às suas tradições. Os alimentos que exprimem uma dinâmica intricada com aquelas vivências prazerosas na roça são certamente mais valorizadas que aqueles alimentos e comidas que são, dentro das concepções da classe médica, enquadrados como "saudáveis".

6 Como será explorado mais adiante, as concepções sobre saúde adotadas pelos mineiros diferem significativamene das percepções expressas pelos médicos e nutricionistas. O atributo "força", indissociavelmente associado com frescor e vitalidade, constitui um parâmetro para aferir o nível de salubridade de um determinado alimento. A maior parte dos mineiros classifica as comidas mais industrializadas e repletas de "químicas", que são encontradas no contexto da cidade, como "comida fraca", cujo consumo, a seu ver, pode provocar um processo de adoecimento. 


\subsection{A lembrança saudosa traduzida em práticas agrícolas}

A lembrança saudosa não apenas registra a ausência daquilo que viveu, mas é traduzida em atos que recuperam, de algum modo, as vivências vinculadas com esta roça que se constrói e reconstrói nos jogos de memória. Para os que nasceram e foram criados na área rural, as práticas agrícolas representam um dos modos de dar continuidade às experiências vivenciadas anteriormente como agricultores e trazer alguns fragmentos do universo da roça para o ambiente da cidade. Ao mesmo tempo, tem um vinculo estreito com os hábitos alimentares; a lembrança saudosa de determinados alimentos que eram componentes da mesa farta na roça se traduz em um esforço consciente de trazê-los para o ambiente da cidade e plantá-los nos quintais.

Tatiane, oriunda de Governador Valadares, MG, afirma que seu quintal, repleto de uma diversidade de plantas, flores e árvores frutíferas, é igual à roça.

Agora fiz um muro. Mas, antes de ter o muro, se olhar para frente - tem mata. Mas é a mesma coisa. O verde lembrava de lá - a fazenda do meu pai - tinha muito capim, era verdinho. Talvez por isso, gostei muito daqui. Lembrar do passado me faz bem. Aqui no quintal me dá a sensação de ser roça. Aqui, se não sair para rua, não vejo ninguém. Estou aqui na minha roçinha [Tatiane].

Desta maneira, ela tem conseguido construir um espaço na atualidade que lhe remete à vivências anteriores. Este gesto representa uma conciliação interna entre dois espaços e dois tempos. Isto é, um passado idealizado não precisa ser procurado num tempo perdido - está incorporado no quintal, pelas plantas que compõem a passagem do seu presente.

Para Dona Rosa, de Ubaporanga, MG, que afirma que "plantar é uma forma de lembrar o passado", retomar a atividade agrícola no meio urbano tornou-se uma válvula de escape para finalidades de relaxamento, distração e lazer:

Agora estou voltando a plantar. Deu aquela coragem. Fátima, minha filha, fala: 'Mãe, você tem a cabeça quente, mexendo com tanta planta. Eu falo... oi, as plantas são vivas, né? A gente conversa com elas.. a gente distrai muito. Olhando para as plantas, até o aborrecimento acaba. A gente sente que tem vida. Ela acha que poderia estar passeando, me distraindo. Falo que prefiro ficar plantando que passear. [Rosa]
Nunca fui de ensinar muito para minhas filhas, mas elas viram como que era. Dava muito couve. Falam que é bobagem porque pode comprar couve - é tão barato. Aí, eu falo assim: É barato, mas eu posso até evitar comprar e vou conviver com ela - o que é tão bom... me alegra muito. [Rosa]

Estas falas exprimem a alegria que é suscitada pela convivência com as plantas, uma atividade que, para Dona Rosa, é preferível a um passeio. A partir de seus experimentos com plantio, Dona Rosa demonstra que aquelas vivências tidas na roça não se estancam como se fosse um mero legado que se deixa "lá" como resquício de um passado alheio diante dos processos de deslocamento. A atualização de práticas agrícolas no ambiente da cidade envolve uma re-adaptação de saberes e técnicas para um novo processo contextual, repleto de outras condições sócio-ambientais, o que necessariamente implica em uma reestruturação de significados.

Vários mineiros comentam que, apesar de gostar muito de plantar, sentem-se impedidos de experimentar o plantio devido às limitações inerentes aos espaços do ambiente urbano. Esta sensação acerca da limitação do espaço, está embasada num contraste que se estabelece com as condições da roça, onde os mineiros lembram da maior extensão dos espaços para plantio - seja no roçado, seja no quintal. ${ }^{7}$ Portanto, é difícil cogitar a possibilidade de "dar certo" quando se realiza a plantação nos espaços pequenos e limitados, que compõem o âmbito doméstico (frente da casa, laje, terraço).

Todavia, enquanto alguns mineiros desistem de plantar pelas limitações físicas que são postas, há outros que estão dispostos a desenvolver experimentos para plantio em espaços pequenos e apertados. Dona Ivone, por exemplo, afirma que, mesmo "não tendo onde plantar, a gente sempre dá um jeito. Arruma latinha e pega muda com uma vizinha, ou lá no Casarão, onde tem muitas plantas". Os mineiros que se dedicam à plantação estão o tempo inteiro experimentando - criando novos arranjos para as plantas a partir de diversos tipos de materiais que se encaixam em vários cantos - em cima da laje, em frente a casa e assim por diante. Seus experimentos variam desde a experiência de pegar uma muda no meio do mato e transplantá-la para uma lata na entrada da casa até a vivência de criar um arranjo de diversos recipientes para suspensão de plantas, num sentido vertical.

Todas estas invenções atestam a força criativa dos sujeitos envolvidos. $\mathrm{O}$ ato de plantar no meio urbano envolve alterações não apenas nas técnicas e recursos utilizados, mas também no uso dos espaços do âmbito

7 É importante fazer referência aos significados atribuídos aos espaços utilizados para plantio no contexto da roça - roçado, quintal e pomar - para analisar os usos dos espaços disponíveis no ambiente urbano. Dona Rosa discorre sobre as funções de cada um destes espaços no mapeamento da roça. O roçado é um espaço considerado extenso, mais afastado da casa, onde "se planta milho, feijão e café" ; o pomar é um espaço voltado para plantação de frutas; e o quintal geralmente fica próximo a casa, onde se faz a horta. A horta geralmente é de "verdura e cheiro verde", mas pode também incluir ervas medicinais. 
doméstico. Espaços que, anteriormente, não eram visualizados como possíveis lugares para plantio assumem esta função, como é o caso da laje ou do terraço.

\subsubsection{O fluxo de dar e receber / pedir e oferecer - a construção de um circuito social}

Uma das atividades que observei com bastante frequência ao longo do meu trabalho de campo foi a circulação de insumos entre as pessoas que se deslocaram para a cidade e aqueles que ficaram no lugar de origem, ou entre as pessoas que plantam ou gostam de planta dentro das comunidades de Morro dos Prazeres e Escondidinho. De algum modo, o fluxo de dar e receber ou pedir e oferecer mudas e sementes representa uma cadeia de ações que possui um efeito multiplicador, isto é, gera um circuito social. Neste trânsito constante, como mostrarei a seguir, existem múltiplas possibilidades de interação, que refletem um impulso criativo, voltado para a multiplicação dos conhecimentos e práticas adquiridas a partir de vivências tidas na área rural. O que é interessante observar é de que modo todas estas trocas - tanto de objetos - sementes, plantas e alimentos - quanto de informações sobre seus múltiplos usos - intensificam não apenas o espírito de experimentação que caracteriza as práticas de plantio e colheita, mas também os processos de sociabilidade, geradores de vínculos sociais.

Inúmeras vezes, nas minhas andanças com Dona Rosa, observei ela pedindo mudas de couve ou taioba quando eram encontradas nos quintais dos mineiros visitados. Quando Dona Rosa ficou sabendo que Dona Ana já tinha ido embora, devido à remoção forçada, por morar próximo ao lugar onde ocorreu o deslizamento ${ }^{8}$ de terras, ela expressou tristeza porque queria ter pegado algumas mudas no seu quintal antes de sua saída - especialmente obobro ${ }^{9}$, uma espécie cada vez mais dificil de encontrar nos arredores do Morro dos Prazeres. Dona Rosa também contou que plantou uma muda de manjericão no terraço e que ela, finalmente, estava se firmando, de modo que "já dava para fazer outras mudas". Ela oferecia as mudas a algumas vizinhas durante as visitas realizadas: "já estou com sete mudas de manjericão lá em casa - todas bem bonitas".
Dona Rosa também frequentemente fazia idas semanais para o Parque da Tijuca ${ }^{10}$, distante cerca de 5 $\mathrm{km}$ de sua residência, com sua vizinha sergipana Dona Arlete, com o intuito de colher diversas plantas nativas como capiçoba, obobró, taioba e frutas (jaca, abacate, banana, manga verde), que dificilmente poderiam ser encontradas nos quintais e lotes vagos. As plantas e os alimentos que foram coletados no mato sempre eram distribuídos entre os vizinhos ao nível local, depois de retornar das caminhadas.

Quando passei um período de trabalho de campo em Ubaporanga, o lugar de origem de muitos mineiros enraizados em Morro dos Prazeres, notei que a troca de mudas e sementes era também um dos assuntos principais nas conversas. Em uma ocasião, Dona Rosa perguntou para seu padrinho de casamento se tinha recebido as sementes de mamão, oriundas de sua plantação em cima do terraço, trazidas por Marlene, sua irmã. Na hora de ir embora, Dona Rosa também levou várias mudas, encontradas no quintal de Marlene, além de diversos alimentos, doados por vizinhos e familiares, como banana, grãos de café e feijão colhido.

$\mathrm{Na}$ maior parte dos casos, os moradores falam apenas da doação de mudas, sementes e alimentos e não enfatizam o que "ganham em troca". Entretanto, parece haver um intervalo de tempo entre as duas ações - dar e receber - o que sustenta a lógica da não-obrigatoriedade da retribuição. Talvez seja um dos princípios que garante o equilíbrio entre as relações sociais costuradas.

As dimensões das relações forjadas a partir das modalidades de troca aparecem de forma explícita na narrativa da Ana Maria:

Muitas coisas que tem aqui minha mãe trouxe de Minas. Trouxe três tipos de cana, três tipos de banana, pé de limão, muda de couve, manga e semente de abóbora. E tudo saiu bem aqui... até morango. Aqui a terra é muito boa. Não sei como minha mãe conseguia morango oi, que coisa linda! E ela falava assim - já que lá em Minas me deram todas estas plantas, não vamos guardar para nós - vamos dar para os outros. Ela sempre estava dando. Ela foi embora mas eu continuei com as plantas. Não sei como as pessoas descobrem....fazem fila para pedir. $\mathrm{O}$ tempo todo pedem. E as pessoas pedem porque eles plantam. Cada hora trazem alguma coisa - às vezes demora, mas depois vêm com alguma mudinha,

8 Em abril de 2010, chuvas intensas provocaram o desabamento de casas e causaram 21 mortes. A intervenção estatal, no período pós-crise, era pautada numa estratégia de remoção de famílias que eram mais expostas à situações de risco, por estarem localizadas próximas ao local do deslizamento.

9 Obobro é o nome usado pelos mineiros entrevistados - em vez de "orapronóbis", outro nome para esta planta, difundido amplamente. É uma planta nativa bastante valorizada na culinária.

10 o Parque da Tijuca tem uma extensão de de 3,953 ha de Mata Atlântica e é considerado uma das maiores florestas urbanas do mundo. Uma das entradas do Parque está localizada próxima ao Bairro Santa Teresa. Entre Morro dos Prazeres e o Parque, há apenas uma distância de 5 km., o que facilita o acesso dos moradores, para que possam dar continuidade às suas práticas de extrativismo. 
alguma verdurinha do seu quintal - ou um pedaço de bolo. Com Sr. João por exemplo, como ele ama planta, está sempre trocando comigo. Quando colhe banana, ele me dá...quando a gente colhe, a gente dá. Às vezes ele empresta uma ferramenta para mim - e eu depois mando para ele um montão de couve. Mas, tudo isso por causa da planta. Porque ele gosta de planta e nós também gostamos de planta.

Ao explicar como a mãe foi trazendo mudas e sementes da roça para fomentar sua plantação no meio urbano, Ana Maria mostra claramente de que forma uma ligação com as práticas agrícolas é cultivada entre as gerações, ultrapassando as fronteiras geográficas. De certo modo, há um conjunto de conhecimentos, práticas e vivências que são repassados da mãe, oriunda da roça, para a filha, que nasceu e cresceu no âmbito urbano. Esta transmissão transgeracional vai além das relações de parentesco; as outras relações sociais também são intermediadas pelas plantas - isto é, acontece "tudo isso por causa da planta". A vizinhança se envolve neste circuito intenso de trocas, baseado em um sistema de reciprocidade, pois "as pessoas pedem porque também plantam" e tem, portanto, condições de retribuir. Isto posto, há critérios que determinam a aceitação dos pedidos. Quem pede geralmente já participa deste jogo de dar e receber, oferecer e pedir.

\section{Comida carioca e comida mineira: marcas classificatórias que regem o trânsito rural-urbano}

Um enunciado que orientou minha navegação por este universo social foi em relação às mudanças ocorridas nos hábitos alimentares a partir do processo de enraizamento das famílias mineiras nas comunidades de Morro dos Prazeres e Escondidinho - as rupturas, transformações e ressignificações.

A seguir, analisarei o que se sustenta e o que se transforma neste fluxo rural-urbano, tendo como foco as opções alimentares - focalizarei as classificações alimentares, os enquadramentos das comidas nas refeições e as representações sociais da "comida da roça" / "comida mineira" / "comida da cidade" / "comida carioca".

\subsection{As marcas das classificações alimentares}

Os mineiros concebem a comida a partir de determinadas classificações. No ato de classificar, o que importa não são os agrupamentos, mas as relações que são estabelecidas entre as categorias (Lévi-Strauss, 1976, 2003). Isto é, tomo como referência a definição das classificações sociais como uma força ordenadora do mundo social (Bourdieu, 1990) haja visto que, para os pesquisados, a classificação é uma forma de organizar as relações forjadas com o alimento e a comida.

As classificações sociais como acontece nas sociedades arcaicas que operam, sobretudo, através de oposições dualistas - masculino/feminino, alto/baixo, forte/fraco, etc. organizam a percepção do mundo social e, em determinadas condições, podem realmente organizar o próprio mundo (Bourdieu, 1990, p.165)

Nesta parte, o foco de minha análise reside nos significados atribuídos a determinados alimentos e como estes significados se agregam em torno de algumas categorias, de que forma são estabelecidas convergências e contrastes entre estas categorias e até que ponto as novas condições vigentes, a partir do deslocamento para a cidade, interferem nas apropriações efetivadas.

\subsubsection{Forte/fraco}

A noção de "comida forte" - aliada à roça - se embasa no seu contraste com "comida da cidade" - como revela o depoimento da Dona Lúcia, oriunda de Ubá, quando perguntei sobre seu estado de saúde:

\footnotetext{
Não tenho nem anemia. Porque comia bem na época. Porque a comida era forte. Lá tínhamos mais saúde. Lá na roça, pegava o café no pé e botava para secar. Depois torrava. Somente pegava milho, ralava. Fazia feijão - tirava casca e cozinhava. Arroz - limpava no pilão. Tudo o que a gente comia era forte e era da época. Porque não tinha química nem nada.Você pegava no pé.Aquele feijão que hoje está no saco não é fresquinho. Hoje, é diferente porque é tudo pronto. Não tem que dar duro para plantar ou para colher.
}

As classificações dos alimentos são imbuídas de contrastes e paradoxos. O que transparece neste trecho de depoimento da Dona Lúcia é de que forma a classificação "comida forte" está fundamentada num quadro contrastivo entre rural/urbano e passado/presente.

Uma característica que é associada à comida da roça, como se fosse um traço constituinte do próprio alimento, é a noção da "força". Segundo Dona Lúcia, que trabalhava como empregada das fazendas e participava diretamente do processo produtivo, a força dos alimentos que compunham sua dieta na roça se deriva do nível de empenho, no sentido do esforço físico.

É como se a exigência do processo produtivo implicasse em uma maior consistência dos alimentos consumidos. "Colher na época" e "não ter química nem nada" também constituem sinais da maior consistência 
da comida da roça. "Comer bem" significa ter "comida forte" e "ser fresquinho" - o que também representa um escudo contra as doenças e promove "mais saúde". Logo, a salubridade está associada com a ingestão de "comida forte".

No outro polo desta cadeia de significações, residem os alimentos consumidos na cidade, que se destacam por não serem visivelmente conectados com o esforço físico da atividade agrícola e por possuírem "químicas", agrotóxicos e uma série de outros aditivos que extraem as vitaminas, empobrecem o alimento e trazem doenças. Mesmo sem utilizar o termo "fraco", opera-se uma oposição nesta fala. Ou seja, a "comida da cidade" passa a significar negação, relativa ou absoluta, das características da "comida da roça"; há uma perda significativa de sua força, seu frescor, sua vitalidade.

No depoimento de Dona Deca, mineira oriunda de São José do Batatal, a palavra fraco é utilizada a partir da descrição de comida congelada, claramente associada com Rio de Janeiro: "Carne e frango era congelado. Fomos descobrir isso no Rio de Janeiro. Como que pode isso aí? Esta comida é fraca demais. Fica parado ali”".

A linha divisória entre forte/fraco está ancorada nas noções de saúde/doença, de tal forma que parece haver uma distinção entre processos de saúde, associados com a força, e processos de adoecimento, associados com fraqueza. Alguns alimentos, vistos como mais fortes, supostamente são mais saudáveis, enquanto alimentos fracos contribuem para o enfraquecimento do organismo e o surgimento de doenças.

Este pensamento se exprime de uma forma mais nítida quando as entrevistadas destacam a maior incidência de diabetes e outras doenças crônico-degenerativas como hipertensão e obesidade logo depois da vinda para a cidade. $\mathrm{O}$ depoimento de Dona Margarida, oriunda de Carangola, em relação ao seu processo de adoecimento, ilustra esta questão:

Lá na roça, eu nunca fui doente nem nada. Ninguém ficava - nem minha mãe, nem meu pai. Minha mãe, às vezes, pegava planta no mato para fazer chá quando ficava gripada, mas não passava disso. Depois de vir para cá, o médico me falou que estava com diabetes. É ruim demais. Não posso comer isso, não posso comer aquilo... tive que cortar muita coisa. Acho que fiquei assim porque passei a comer mais carne vermelha, massa, doces - coisas que não comia lá na roça. Aquelas comidas fortes - couve fresquinho, angu feito de nossa fubá - não tem mais do jeito que era. [Margarida]

Dona Margarida, como muitas outras entrevistadas, cita o maior consumo de "alimentos fracos"- carnes congeladas, enlatados, massas, empadas - como um fator determinante no seu processo de adoecimento.
Woortmann (1990), em seu trabalho Com parente não se neguceia ${ }^{11}$, aponta este fenômeno como uma tendência da própria modernização, associada à industrialização e à mecanização das práticas agrícolas e alimentares, já que, em suas palavras: “com a modernização, a terra, a comida, os corpos das pessoas e o corpo social se tornam fracos" (Woortmann, 1990, p. 45).

As lembranças pintam um quadro pitoresco em relação à saúde da população que reside na área rural. A força das comidas que se consome na roça, junto com o ar puro e o contato com a natureza parecem ser fatores agregadores para um estado de saúde plena. Em suma, se deslocar para cidade parece ser análogo ao processo de adoecimento, visto pelo prisma das categorias alimentares.

Nota-se que esta relação entre processos de saúde e doença e as categorias alimentares ganha seu contorno por meio das prescrições de uso de determinados alimentos em diversos tipos de situações. Seria o caso das percepções em torno do período pós-parto.

Segundo Dona Rosa, na roça, depois do parto, a mulher deveria comer apenas comida "fraca", que consistia nos seguintes alimentos: água de fubá e sopa de galinha. Comida "fraca" era sempre relegada às pessoas "doentes" e a mulher no período pós-parto, por ter perdido muito sangue e por passar por um estágio de recuperação, era enquadrada como uma pessoa "doente".

Portanto, durante 40 dias, ela era privada das comidas consideradas "fortes" - que seriam verduras, arroz, feijão e carne de porco - até depois do período de "resguardo".

A vida no meio urbano impulsionou modificações na apropriação das categorias forte/fraco, no caso do período de "resguardo". Dona Rosa conta que, na cidade, o período de resguardo não é cercado dos mesmos cuidados. A mulher depois de dar a luz não é tratada como se estivesse doente e pudesse apenas aguentar comidas mais fracas. O seguinte trecho de depoimento é significativo sob este aspecto: "Tive sete filhos aqui no Rio. Aqui, se acaba de ter neném e já te dão farinha, carne assada - comida forte. Eu podia comer de tudo lá no hospital. Adorava. E logo depois, já estava trabalhando de novo".

O que merece destaque é que estas categorias forte/fraco - não são abdicadas a partir do fluxo rural-urbano. Em alguns casos, como foi ilustrado acima, há uma inversão nas representações. Isto é, no período de resguardo, no contexto da cidade, a mulher tem permissão para comer "comida forte", em vez de se restringir apenas à "comida fraca", como era a prescrição para esse momento da vida reprodutiva da mulher na área rural. No entanto, o que se ressalta aqui é que, mesmo que haja uma inversão nas representações, a matriz ideológica, subjacente a estas categorias, se opera no âmbito urbano com a mesma intensidade. 


\subsubsection{Fartura}

Fartura é um operante que exerce uma função classificatória, sendo que há alimentos associados com "épocas de fartura" e outros adquiridos em condições de maior escassez ou aperto. $\mathrm{O}$ que cumpre destacar aqui é que, mesmo que os informantes não usem sempre este termo, muitas vezes falam de coisas que remetem à ideia de fartura.

Nas falas, fartura transparece não apenas como uma grande quantidade de alimentos - "era muita comida”, "lá não passávamos necessidade" - mas também remete à ideia de diversificação dos bens alimentícios - pois "tínhamos de tudo", "tinha muita fartura das coisas". ${ }^{12}$ Desta forma, embora seja um componente ideológico presente nos discursos, a noção de fartura está imbuída de ambigüidade. Isto é, os registros de uma "época de fartura" se localizam em diversos pontos deste fluxo entre o tempo atual e o passado.

Fartura não está associada, necessariamente, às melhores condições financeiras, pois há uma série de fatores que interferem na imagem forjada da "mesa farta". Por um lado, a mesa farta sublinha a autonomia que o(a) agricultor(a) exerce sobre o processo produtivo e por outro, o nível de acesso que se tem a um mercado que oferece uma maior abundância e diversidade de alimentos.

DonaVilma, oriunda de Caratinga elucida a sensação que este novo cenário provoca no contexto da cidade:

Levei um susto quando cheguei aqui, porque não estava acostumada a ver tantas coisas - muitas coisas que nunca vi antes. Quando fui para o sacolão pela primeira vez, vi muitas verduras e frutas diferentes - coisas que não conhecia antes. Lá na roça, não tinha cenourinha. Não era comum na roça. Batata baroa - era o que a gente considerava como cenoura. Lembro uma vez meu pai decidiu plantar cenoura - até ficou bonito. Deu tanta cenoura! Sabe como minha mãe fazia? A gente não sabia o que fazer com aquilo. Ela cortava e fritava - ficava murchinha. Depois que aprendemos que era para comer cru ou cozido! Lá somente tinha aquela abóbora-de-água. Beterraba também - não conhecia lá. Outra coisa que não conhecia lá - caqui. E quando fui ao supermercado - nossa! É tão grande - e tem de tudo! Tantas marcas diferentes - nem sabia o que deveria comprar. Ficava perdida - porque tinha que escolher... e eram tantas opções. [Vilma]

O susto que Dona Vilma sentiu quando entrou nos estabelecimentos do mercado local surge a partir do seu enfrentamento com um novo contexto, no qual são encontrados produtos que não conhecia, anteriormente, lá na roça. Logo, há uma descontinuidade entre suas experiências anteriores na roça e sua vida na cidade que fica evidente ao lidar com uma maior complexidade de produtos e tipos de comércio.

Ao relatar sua primeira ida ao supermercado - um espaço de "tantas marcas diferentes" que "nem sabia o que deveria comprar", pois "não estava acostumada a ver tantas opções" - Dona Vilma revela claramente as mudanças que surgem a partir de sua inserção num universo voltado para o consumo.

No contexto do Morro dos Prazeres e Escondidinho, os mineiros em questão mencionam a compra com bastante frequência - como sendo uma garantia de acesso a um maior leque de opções. A "mesa farta" é potencializada a partir da vivência na cidade, isto é, as múltiplas opções de comércio no espaço urbano proporcionam o maior acesso a uma gama ampla de alimentos.

Há uma ligação entre o poder de compra e a fartura. É como se uma ampla gama de alimentos fosse garantida por meio do trabalho realizado. Parece haver a ideia de que o trabalho, como categoria, abre todas as portas num mercado repleto de múltiplas opções de comércio, que se norteia pela noção de "livre escolha"13

Por outro lado, para muitos mineiros entrevistados, oriundos da região de GovernadorValadares e Zona da Mata - que viviam a condição de sitiantes ou trabalhadores em fazendas - a roça traz lembranças de uma alimentação rica, tanto em termos de quantidade quanto em termos de qualidade. O seguinte trecho de depoimento, da Dona Vitalina, oriunda de Alpercata, revela esta perspectiva sobre a fartura:

Lá não passava dificuldade. Arroz colhia - preparava em casa. Feijão, a mesma coisa. Milho, a gente colhia. Lá também pegávamos aquelas frutas - nem tinha onde espremer. Tinha uma bacia grande. Botava. Deixava lá um pouco e chamava todo mundo - todo mundo sentava ali para se alimentar de frutas. Como era bom! Tinha de tudo - podíamos comer à vontade. [Vitalina]

Diante do valor da compra no ambiente urbano, persiste, no outro pólo, uma noção elástica em relação aos outros valores inerentes ao alimento na área rural, que não passa pelas conotações monetárias. $\mathrm{O}$ fato de que a maior parte dos alimentos da roça não precisam ser comprados é um ponto de destaque em várias falas. Como Dona Leda, oriunda de Capitão Andrade, enfatiza:

12 As compreensões nativas em torno da categoria fartura se relacionam com o conceito trazido por Woortmann (1977): "Fartura está referida a bens alimentícios de origens diversas (animal e vegetal), assim como à quantidade dos alimentos de que se pode dispor" (WOORTMANN, 1977, p. 27). 13 Os fundamentos do sistema capitalista estão ancorados no lluminismo dentro do contexto de Europa no século XVIII. Apostava na liberdade individual como canalizador para dar prosseguimento aos seus próprios interesses e promover o crescimento econômico. Portanto, a noção de livre escolha é um elemento constituinte da categoria de trabalho no contexto do sistema capitalista na época moderna. 
Quem ainda mora na roça não tem noção do valor que tem. Aqui tudo é comprado. Lá não. Quando voltava, fazia tanta coisa - ia para os roçados para ver as plantações. Gosto de ver o amendoim para arrancar... ia e ficava muitos dias. Pensava assim - na cidade, se quiser fazer suco tem que comprar e aqui posso pegar no pé e fazer na hora.

Para outro informante, Seu Antônio, ex-trabalhador nas fazendas da região de Zona da Mata mineira, a fartura é um elemento-chave nas suas recordações; não obstante, ele lembra que nem sempre era garantida. Ele fala da fartura como se fosse uma característica mutável e volátil, pois "tinha dias que o milho fartava [sic]... e outros dias que não tinha”.

No contexto da roça, como atesta o Seu Antônio, as condições oscilantes do processo produtivo e os fatores climáticos interferiam no rendimento da produção, o que determinava a fartura ou a falta de fartura. No caso da cidade, os fatores que contribuem para a flutuação na quantidade e qualidade dos alimentos adquiridos (o acesso à "fartura") são as oscilações tanto nos preços dos produtos, quanto na condição financeira dos consumidores. O que é interessante notar é que em ambos contextos, não há garantia que haja um provimento de alimentos diversificados na quantidade desejada ao longo prazo: isto é, diversos fatores interferem para que haja ou não haja fartura.

\subsection{O prato típico: "Comida carioca" x "comida mineira"}

Nas minhas indagações, ao perguntar o que vinha à mente quando se visualizava o prato carioca, ficava bastante explícito nas respostas o lugar de ausência que a refeição carioca ocupa. Isto é, o que tem na comida mineira, não tem na comida carioca - uma é construída a partir da falta do outro. Neste sentido, as seguintes citações exprimem os significados associados ao prato carioca:

- O que é o prato carioca? Batata frita com arroz. "É tudo branco, amarelo. Não tem cor. Somente tem salada de tomate. [Dona Antônia, oriunda de São José da Pedra Bonita, MG]

- Já acostumamos com comida carioca. É macarrão, é bife com fritas. Macarrão bem soltinho. [DonaVilma, oriunda de Caratinga]
- Meus filhos são cariocas. Não gostam de verdura não. Carioca gosta de carne, batata frita, arroz, feijão e carne de boi. [Dona Deca, oriunda de São José de Batatal]

$A$ comida carioca adquire significados a partir de sua relação de oposição com a comida mineira. Isto é, ao deparar-se com uma série de diferenças em relação à comida que conheciam na roça, os mineiros, no momento de sua chegada, evocam a categoria "comida carioca" para distinguir da "comida da roça". O que se nota neste processo de diferenciação, é que a mineiridade ganha novos contornos.

Há um enunciado da comida mineira. Características são delineadas e traços se tornam definidores desta culinária. Esta suposta unidade em relação à comida dos mineiros não é dada, a priori, mas este enquadramento se dá justamente a partir da vivência dos contrastes.

Começo por uma análise da refeição principal - o almoço - como operante que possibilita visualizar o que constitui a comida mineira. É possível reconstruir uma imagem do prato típico, a partir das lembranças que foram relatadas, dos tempos vividos na roça. Busco evitar uma possível homogeneização dos hábitos alimentares; entretanto, a partir dos relatos, transparecem os elementos-chaves deste prato: feijão, angu, canjiquinha ${ }^{14}$ e verduras.

Vale salientar que angu é considerado imprescindível na composição das refeições: para os mineiros em questão, o prato “tem que ter angu”. É o fator complementar que preenche as lacunas da refeição, diante de outras carências. Nas palavras de Rosângela, nascida em Morro dos Prazeres e filha de pais mineiros: "Angu era uma coisa que ajudava na comida. Porque, às vezes, não tinha mistura ${ }^{15}$. Não tinha carne. Aí, a gente fazia angu para aumentar a comida”. Em muitas histórias contadas, angu aparece como um elemento que ajudava, especialmente, na época na qual os mineiros chegavam à cidade e "passavam necessidade". É descrita como uma comida "forte", que "mata a fome".

\subsubsection{Carne: uma raridade ou algo indispensável?}

Há um processo de tensionamento entre a verdura e a carne neste referencial contrastivo entre a roça e o momento atual. Isto é, diferentes pesos são atribuídos a cada um, dependendo do processo contextual.

No contexto da roça, o que mais se consumia era carne de porco ou galinha, por serem animais criados lá

14 Canjiquinha é descrita como uma comida salgada - milho quebrado. Na roça, era preparada no lugar de arroz em algumas ocasiões. Dona Rosa conta que, às vezes, é feita com costela de porco.

15 Aqui "mistura" se refere à verduras. É um termo muito utilizado no discurso dos mineiros. 
e, assim mesmo, não eram consumidos todos os dias. Há depoimentos que refletem uma sensação de nostalgia em relação à criação de animais e ao consumo de carne de porco e galinha "fresquinha" - contrapontos com as carnes congeladas que são vendidas na cidade.

A escassez de carne na roça é expressa por Dona Leide - oriunda de Ubaporanga e ex-empregada nas fazendas: "Carne era difícil na roça porque não existia todo tipo de carne. Havia um pedaço de carne por semana - algo assim". A dificuldade de ter acesso a vários tipos de carne, em parte, explica sua pouca frequência na alimentação cotidiana. Enquanto a carne não esteve sempre presente na refeição, a verdura era um traço definidor da comida mineira, porque "é o costume" como a seguinte fala de Dona Maria, oriunda de Senador Firmino, MG revela: "Não deixa de ter verdura. É o costume. Sempre tem. Tem gente que come só arroz, feijão e macarrão. Estas coisas. Parece que a gente não comeu. Tem que ter verdura, legume".

A carne é o elemento-chave do modelo contrastivo estabelecido entre a comida da roça e a comida da cidade. Enquanto na roça, a verdura sempre ocupava um lugar de centralidade no prato, na cidade, a comida carioca é caracterizada pela ênfase atribuída à carne na refeição. Toninho, irmão da Dona Rosa, enfatiza este ponto:

Aqui se come carne todo dia. Lá era somente para o dia de domingo. Era especial carne de domingo... e parece que era mais gostoso. Dizem que mineiro come muita gordura, muita carne de porco. Mas tem aquele dia da semana... não é todo dia. Aqui carne é a mesma coisa que verdura - carne é a mesma coisa que batata. Não sabe chegar ao fogão sem ter alguma carne... [Toninho]

\subsubsection{Verduras: meros enfeites no prato?}

Como fator de diferenciação, os mineiros entrevistados enfatizam o fato de que, na comida carioca, as verduras apenas representam enfeites no prato. Ivone, mineira oriunda da região de Governador Valadares, explicita as diferentes significações que os cariocas atribuem às verduras, no seguinte depoimento: " $\mathrm{Na}$ comida mineira sempre tem que ter verdura - e a verdura fresquinha... colhida na hora. O carioca fala: "Não sou lagarta para comer verdura. Lagarta que come as verduras. Carioca que fala isso".

Outro ponto que merece destaque é a interpretação dada à verdura. No contexto da comida carioca, é reduzida à "alface e tomate", enquanto, quando se trata da comida mineira, há uma maior diversificação nas escolhas feitas e um apreço por algumas espécies, como a couve e a variedade de plantas nativas ${ }^{16}$.
Para o Sr.João, oriundo de Espera Feliz, plantas nativas brotam da terra naturalmente, o que ilustra o potencial da terra para gerar, porque "nem tudo tem que ser plantado". Apresento o seguinte diálogo entre o Sr. João e Dona Rosa sobre a variedade de espécies de plantas nativas que "nascem no mato" e que remetem aos seus tempos vividos na roça:

J: Nascia caratinga na queimada. Lembro até hoje. Deus é bom... deixou tanta coisa boa. Nasce tanta coisa boa da terra, sem plantar. Os cariocas não entendem isso - que nem tudo tem que ser plantado. Que podemos aproveitar do que a natureza nos dá - a terra nos dá tanta coisa boa".

R: "Eu lembro de caratinga. É uma batata. Minha mãe ralava aquilo e fazia bolo. Era gostoso!

J: E caruru de viado? Nossa... a gente ia para mato sempre para pegar. Minha mãe pedia - ela adorava. Eu não acho muito bom. Deixa um gosto estranho na boca.

R: E beldroega? Aqui perto acha muita beldroega. É boa para salada".

J: "Tem muito por aqui. Mas o povo carioca acha que tudo é mato. Não conhece.

R: O que mais gosto é de serralha. Lá em Minas, ocupa muito espaço a serralha. Outro dia achei muito lá pro lado do Casarão.

J: Lá na roça a gente sempre comia serralha com angu. É bom com angu [João e Rosa]

$\mathrm{O}$ que merece destaque no diálogo apresentado acima é a sensação, expressa por Seu João, de que "os cariocas não conhecem" e "não entendem" este universo de plantas e "acham que tudo é mato". Para ele, há uma série de códigos sociais que "o povo carioca" não consegue decifrar. Portanto, ele estabelece demarcações entre os cariocas e os mineiros embasadas no nível de conhecimento que cada um possui acerca das plantas alimentícias e suas diversas funções.

Nas minhas andanças com Dona Rosa pela comunidade e nas suas visitas nas casas de vizinhos, ela falava sobre as plantas nativas com bastante frequência: quais eram os pontos para encontrá-las e como prepará-las. Além de serralha, ela sempre ficava à procura de capiçoba, taioba e obobro - plantas alimentícias que "ficam bem gostosas" ao lado do "angu bem feitinho". Como foi analisado na seção 2.2.1, os mineiros se unem na procura destas plantas nos quintais, nas áreas públicas 
(lotes vagos, etc.) e no mato circundante. Estas plantas, que brotam com naturalidade em diversos ambientes, enriquecem seu prato e diversificam sua culinária.

\subsection{A Refeição enquanto processo social: A comensalidade}

\subsection{1 "Comer juntos"? - tensões em torno das diferenças geracionais}

Quais são os significados atribuídos à refeição enquanto processo social? A refeição revela uma dimensão ritual, pois é constituída de atos simbólicos, com significados partilhados por todos os envolvidos. Ao longo da pesquisa realizada, evidenciou-se que a comensalidade - o ato de "comer juntos" - pode se tornar um momento de disputa de diversos interesses, no qual transparecem as tensões em torno das diferenças geracionais.

Segundo Dona Rosa, diariamente, a hora de almoço se tornou um processo de tensionamento com seu filho por causa das diferenças de gostos e preferências. Ela descreve como seu filho, que trabalha à noite e apenas acorda na hora de almoço, rejeita a maior parte da refeição preparada e sempre sai para "comprar fiado", no armazém da esquina, um pedaço de linguiça para fritar. Ele apenas come o feijão e arroz preparado pela mãe.

Ela enfatiza a atitude individualista dele, quando sai para procurar "sua própria comida" diante de um contexto que, para ela, é extremamente coletivo - o ato de "comer juntos". Como ela afirma:

Ele não é igual à gente, que gosta de verdura. Não foi criado na roça. Ele sempre quer alguma coisa gordurosa, e diz que se não tiver carne, não serve. Já é bem carioca. E não faz diferença para ele sentar com a gente para comer. Ele somente quer comer as coisas que ele gosta e pronto - não está nem aí para o resto.

O que está em jogo na situação retratada é a atitude de rejeição das comidas consideradas tradicionalmente mineiras por parte de um filho que "já é bem carioca", nos termos da Dona Rosa. Aqui há uma demarcação claramente estabelecida entre duas categorias identitárias: carioca vs. mineiro - que em grande parte é determinada pelos gostos e costumes alimentares.

O que vale ressaltar é que o ato de rejeição do filho não sinaliza apenas a recusa de comer comidas mineiras, preparadas pela mãe, mas também pode ser interpretada como uma rejeição daquele momento voltado para a comensalidade no contexto familiar. Ou melhor, o processo de tensionamento vivenciado pela Dona Rosa com seu filho gira em torno não apenas do conteúdo das refeições, mas também dos significados associados à comensalidade, enquanto processo social. Para Dona Rosa, tal recusa de participar do momento ritualizado de "comer juntos" parece ser uma ofensa que ataca os alicerces de suas tradições alimentares, que de algum modo, precisam ser repassados para a nova geração para que não se desvaneçam com o passar do tempo.

\subsubsection{A comensalidade enquanto veículo de socialização em eventos coletivos}

A comensalidade representa um veículo de socialização, isto é, contribui ativamente para a sedimentação de vínculos sociais. Neste sentido, a comida pode ser um indicador dos códigos sociais que regem os eventos coletivos, tanto na roça quanto na cidade. Determinadas comidas como, por exemplo, galo com macarrão, canjiquinha, pé de moleque estão sempre associados aos momentos vividos coletivamente como mutirões ou festas religiosas.

Neste sentido, é interessante observar de que forma o momento de finalização dos mutirões, realizados para efetivar as obras em Morro dos Prazeres, era marcado pela partilha de comidas, uma situação análoga do que acontecia nas "festas de acabamento" dos mutirões nas lavouras. Os nexos entre esses dois tipos de eventos, de cunho social, realizados no passado e no presente, são revelados no desenvolvimento das histórias contadas.

Ao ouvir uma conversa entre as mineiras Dona Rosa e Dona Dalva, percebe-se como este paralelo se estabelece, no desenrolar da conversa:

R: Eu lembro quando acabava a lavoura, no último dia, levava aquele galho de café mais carregado e falava que era bandeira. Era quando terminava a apanhação de café. Minha mãe fazia galo com macarrão... aquela panelada de comida que era para a festa de acabamento

D: Aqui em casa, Luiz gostava de fazer estas comidas quando terminavam as obras, os vizinhos todos vinham. Fazia galo com macarrão, canjiquinha... Aqui em casa fazia. Os vizinhos todos vinham comer - ai, meu Deus! [Dalva e Rosa]

Este diálogo, construído a partir da percepção das semelhanças observadas entre dois eventos de cunho social, realizados em âmbitos diferenciados - na roça e na cidade - e em duas temporalidades distintas - no passado e no presente - revela os elementos que sustentam os hábitos alimentares, independente de fatores de tempo e localidade. Dito de outro modo, é no momento da refeição, vivida coletivamente, que as pontes de conexão são estabelecidas entre passado e presente, roça e cidade.

\section{Conclusões Finais}

Embora os mineiros - os sujeitos desta pesquisa - sejam confrontados com algumas situações que parecem reforçar as polaridades entre passado $\mathrm{x}$ presente, 
srural x urbano: ("comida da cidade" x "comida da roça"; "comida fraca" x "comida forte"), este exercício etnográfico revela de que modo muitas destas dicotomias são diluídas e se fundem a partir da prática vivida. Nas trajetórias destes mineiros, cujas referências às práticas agrícolas e alimentares são pautadas em lembranças de um passado vivido na área rural, este passado é incorporado no momento presente e esta imagem da roça não se cristaliza enquanto um fragmento da imaginação, mas passa por um processo de ressignificação em um novo contexto situacional. Pressupõe-se que há formas de ir e voltar na memoria, de trazer o passado para o momento presente e atualizar estas lembranças mediante as práticas sociais.

Ao mesmo tempo em que a inserção no meio urbano implica em continuidades, também uma série de descontinuidades são desencadeadas a partir destes deslocamentos. Ir para cidade traz novidades, requer um processo de adaptação e pode haver uma sensação de estranheza com este universo até então tão desconhecido. Os mineiros passam a ter acesso a um amplo leque de produtos alimentícios no mercado onde prevalece o valor atribuído ao poder de compra; são introduzidos a novos elementos que compõem a comida carioca; e enfrentam as limitações inerentes aos espaços disponíveis para propagar práticas de extrativismo e plantio de plantas alimentícias.

Todavia, o ponto a ser ressaltado ao longo deste trabalho etnográfico é que a necessidade de lidar com os contrastes entre diferentes tipos de comida e formas de se alimentar no meio urbano não significa que há uma ruptura radical com as tradições que marcam $a$ comida mineira, a partir de sua inserção na cidade de Rio de Janeiro. Os pontos de interseção entre o passado e o presente são canalizados de diversas formas e se expressam mediante várias configurações.

Determinadas práticas associadas à partilha da comida ("comer juntos" enquanto família ou preparar comidas para celebrar coletivamente a finalização de mutirões) perduram neste trânsito rural-urbano. Estas continuidades também podem ser identificadas nas representações sociais que giram em torno dos elementos centrais da refeição mineira que se sustentam e perduram no tempo (angu, verduras) e nas categorias e classificações que continuam ordenando o conjunto de relações forjadas com o alimento e a comida na vida cotidiana (forte $\mathrm{x}$ fraco).

As continuidades e permanências que se observam não representam resquícios de um passado imemorial que são transplantados para o momento presente na sua inteireza, sem passar por nenhuma transmutação. O momento presente exige uma capacidade ativa e criativa e incita a inovação de práticas agrícolas e alimentares.

Esta capacidade inventiva pode ser visualizada no circuito de trocas de plantas, sementes, mudas e alimentos neste novo contexto, que tem como ponto de partida os quintais, as áreas públicas e o mato circundante. Além de constituir estratégias para preservar tradições e conhecimentos adquiridos naqueles tempos, tais práticas também são catalisadores do estreitamento de vínculos sociais. Finalmente, podem ser avistadas nas iniciativas de plantio que se materializam em diversos cantos do âmbito doméstico, mediante a junção de vários materiais e recursos - manifestações de um desejo e impulso de plantar que "não morre" e faz com que "a roça parece estar dentro da gente".

Vale salientar que a visão apresentada a partir das trajetórias dos mineiros que se encontram em terras cariocas é de uma mobilidade sem fim, que não se reduz aos deslocamentos apenas espaciais e que possibilita trazer elementos do passado para o momento presente de uma forma dinâmica. Neste sentido, este trabalho parte de uma leitura dos processos de urbanização e dos deslocamentos entre a área rural e a cidade que não se conforma apenas aos termos ditados por uma "grande narrativa pré-concebida". (Comerford, 2006) ${ }^{17}$ Há infinitas formas de vivenciar estes deslocamentos, que constroem uma linha tênue entre o passado e o presente, a roça e a cidade e que vão muito além de um mero trajeto trilhado entre um ponto de partida e um ponto de chegada.

Desarte, a opção por privilegiar o alimento e a comida nesta cartografia do trânsito rural-urbano reside no poder simbólico inerente aos mesmos, enquanto elementos que se destacam nas lembranças e que se remetem à roça-grande ponto de referência destes mineiros que se deslocaram para a cidade. Fazem a costura entre tantos pontos encontrados nestes fluxos e concedem uma sensação de continuidade para trajetórias que, à primeira vista, podem parecer fragmentadas e distanciadas de suas origens.

Afinal, é no cerne das trajetórias destes mineiros - que atravessam as fronteiras entre o passado e o presente, a roça e a cidade, a tradição e a invenção - que as práticas agrícolas e alimentares encontram novas significações e, ao mesmo tempo, se afirmam como traços definidores da identidade mineira. É neste fluxo de "ir e vir" - que se reflete na produção das lembranças - que a identidade mineira se enraiza.

17 A oposição entre campo e cidade, que tem prevalecido em algumas formulações teóricas e metodológicas, vem aliada à antítese tradicional/ moderno, passado/futuro (Sorokin et al, 1965; Lefebvre, 1970). Muitas destas formulações parecem sedimentar a noção de que o êxodo dos trabalhadores rurais do campo implicaria no iminente desaparecimento do campesinato e que as atividades agrícolas, exercidas na área rural, seriam suplantadas pelos processos de modernização da vida urbana. Assim, ao encarar meu objeto de pesquisa, tive que enfrentar uma série de armadilhas nas abordagens sobre a problemática rural-urbano. 


\section{Referências}

AMON, D. \& MENASCHE, R. Comida como narrativa da memória social. In: Sociedade e Cultura, v.11, n. 1, jan./jun., p. 13-21, 2008.

BARTH, F. O guru, o iniciador e outras variações antropológicas. Rio de Janeiro: Contracapa, 2000.

BOURDIEU, P. O poder simbólico. Rio de Janeiro: DIFEL/ Bertrand Brasil, 1989.

Coisas ditas. São Paulo: Brasiliense, 1990.

BRANDÃO, C.R. Plantar, colher, comer: um estudo sobre o campesinato goiano. Rio de Janeiro: Graal, 1981.

COMERFORD, J. Onde está a comunidade? Configurações sociomorais e redefinição dos limites do rural e do urbano. In: Anais da XXVI REUNIÃO BRASILEIRA DE ANTROPOLOGIA, 2006, , 2006. (mimeo)

DURKHEIM, E.; MAUSS, M. Algumas formas primitivas de classificação: contribuição para o estudo das representações coletivas. In: MAUSS, M. Ensaios de Sociologia. São Paulo: Perspectiva, 1981. p. 399-455.

HALBWACHS, M. Les cadres sociaux de la mémoire. Paris: Éditions Albin Michel, S.A., 1994.

. A memória coletiva. São Paulo: Centauro, 2006

HAUCK-LAWSON, Annie. Hearing the Food Voice: An Epiphany for a Researcher. Digest-An Interdisciplinary Study of Food and Foodways, v. 12, n. 1-2, p. 6-7, 1992.

When Food is the Voice: A Case Study of a Polish-American Woman. Journal for the Study of Food and Society, v. 2, n. 1, p. 21-28, Spring, 1998.

HEREDIA, B.M.A. A morada da vida: trabalho familiar de pequenos produtores do Nordeste do Brasil. Rio de Janeiro: Paz e Terra, 1979.

IBGE - Instituto Brasileiro de Geografia e Estatística. Censo Demográfico 2000. Disponível em: http://www.ibge.gov.br: downloads/ estatísticas/ censos/ censo demográfico 2000/ resultados do universo/ agregados por setor censitário. Acesso em fev/2011.

LAMBEK, Michael. "The Past Imperfect: Remembering as Moral Practice”. In: Antze, Paul \& Lambek, Michael. Tense Past: Cultural Essays in Trauma and Memory. London: Routledge, 1996.

LEFEBVRE, H. Du rural à l'urbain. Paris: Anthropos, 1970. LÉVI-STRAUSS, C. Antropologia Estrutural 2. Rio de Janeiro: Tempo Brasileiro, 1976.
. O pensamento selvagem. São Paulo: Companhia Ed.

Nacional, 1976.

. A eficácia simbólica. In:Antropologia Estrutural. 6. ed.

Rio de Janeiro: Tempo Brasileiro, 2003. p. 215-36.

LOURENÇO, Eduardo. Portugal como destino seguido da mitologia da saudade. Lisboa: Gradiva, 1999.

MINTZ, S.W. Sweetness and power: the place of sugar in modern history. New York: Penguin Books, 1986.

Tasting Food, Tasting Freedom. Boston: Beacon Press

Books, 1996.

. Comida e Antropologia: uma breve revisão. Revista

Brasileira de Ciências Sociais, v. 16, n. 47, out. 2001.

POLLAK, Michel. Memória Coletiva e Identidade Social. Estudos Históricos, v. 10, p. 200-215, 1992.

SAYAD,A. A imigração ou os paradoxos da alteridade. São Paulo: EDUSP, 1998.

SOROKIN, P.A., ZIMMERMAN, C.C. ; GALPIN, C.J. (ed.). A systematic source book in rural sociology. New York: Russell \& Russell, 1965.

VELHO, O.G. (org.). Relatório do Grupo de Pesquisa do Museu Nacional (UFRJ): Projeto Hábitos Alimentares em Camadas de Baixa Renda (Convênio FINPEP/FUB/UFRJ). Rio de Janeiro: Museu Nacional, 1977.

WEITZMAN, R. Educação Popular em Segurança Alimentar e Nutricional: uma metodologia de formação com enfoque de gênero. Belo Horizonte: Rede de Intercâmbio de Tecnologias Alternativas, 2008.

WEITZMAN, R. Entre a roça e a cidade: um processo de invenção de práticas alimentares e agrícolas. Rio de Janeiro, 2011. Dissertação (Mestrado em Antropologia Social) - Museu Nacional, UFRJ, 2011.

WOORTMANN, K. Hábitos e ideologias alimentares em grupos sociais de baixa renda. Série Antropologia, Brasília, n. 20, 1978.

; WOORTMANN, E. Campesinato e Saber Agrícola. In: Anais do XXVI CONGRESSO BRASILEIRO DE CIÊNCIA DO SOLO (mimeo), Rio de Janeiro, 1997.

UnB, 1997 O trabalho da terra. Brasília: Editora da

. Com parente não se neguceia: o campesinato como Ordem Moral. Anuário Antropológico 87, 1990. 


\title{
Mineiros in movement: fluctuation of meanings associated with food and agricultural practices in the context of rural-urban transit
}

\begin{abstract}
The objective of this particular piece of work is to analyze the evolution of social representations of food and eating by people originally from the rural areas of Minas Gerais, who have moved to Morro dos Prazeres and Escondidinho - urban communities located in the city of Rio de Janeiro. The values underlying food choices in the urban context - that go through ruptures, transformations and new interpretations - are quite elucidating of the mobility that characterizes this process of "coming and going" in space and time. The connection between the past and the present, between the rural areas and the city is reorganized and restructured through the food and agricultural practices of this population. In such a way, elements from the past gain new meaning in the present moment.
\end{abstract}

5 key words: mobility; memories; food habits; Minas Gerais; countryside.

\section{Los mineros en movimiento: fluctuación de los significados asociados a las prácticas de alimentación y agricultura en el contexto del flujo rural-urbano}

\begin{abstract}
Resumen
El objetivo de este trabajo es analizar la evolución de las representaciones alrededor de la comida y los alimentos por personas que llegaron de la zona rural de Minas Gerais y se fueron a las comunidades Morro dos Prazeres y Escondidinho, ubicadas en la ciudad de Río de Janeiro. Los valores que determinan la elección de los alimentos en el contexto urbano - que pasan por interrupciones, transformaciones, y nuevas significaciones - son reveladores de la movilidad que caraceriza este proceso de idas y vueltas en el espacio y en el tiempo. La conexión entre el pasado y el presente, entre el campo y la ciudad, se renueva y se reactualiza en el corazón de las prácticas de alimentación y agricultura ejercidas por los mineros, en la producción de lo que se refiere al pasado, pero al mismo tiempo, genera nuevos significados en el momento presente.
\end{abstract}

5 Palabras clave: movilidad; recuerdos; hábitos alimenticios; Minas Gerais; campo 